\title{
Immature stages of New Caledonian Tingidae (Heteroptera): Description and development
}

\author{
ERIC GUILBERT \\ Muséum national d'Histoire naturelle, Département de Systématique et Evolution, FRE 2695 CNRS, 45 rue Buffon, \\ F-75231 Paris cedex 05, France; e-mail: guilbert@mnhn.fr
}

Key words. Development, immature stage, Heteroptera, New Caledonia, new larvae, Tingidae, translocation

\begin{abstract}
Second to fifth instars of nine New Caledonian species of Tingidae are described. A key to fifth instars is provided. The comparison of immature stages among the known larvae shows that translocation of marginal tubercles in larvae, considered as the general rule, is absent in New Caledonian larvae. Also, external morphology of larvae becomes more complex through development, by the addition and ramification of tubercles, as it does also through evolution. Such a tendency is reminiscent of a heterochronous phenomenon, like peramorphosis. Translocation phenomenon could be an intermediate stage of evolution in terms of aquiring more tubercles.
\end{abstract}

\section{INTRODUCTION}

Tingidae comprises some 2600 species of tiny phytophagous bugs, all characterized by their lace- like body structure. The systematics and phylogeny of Tingidae are based on adult characters only, although larvae also show useful characters (Lee, 1969; Livingstone, 1978; Péricart, 1983). In fact, very few larvae are known (less than $8 \%$ of the described species). According to some major works on the subject, most of the known larvae are Palaearctic (Štusák, 1974; 1975; Štusák \& Štys, 1959; Lee, 1969; Péricart, 1983), Afrotropical (Duarte Rodrigues, 1977; 1978, 1979), and Oriental (Livingstone, 1978). Very few larvae are known from the Neotropical and Neartic regions, and none is known from Australasian region, with the exception of Tanybyrsa cumberi Drake (cf. May, 1977). Development through instars was poorly studied, except in the studies of Lee (1969), Seidenstücker (1954), and Štusák \& Štys (1959). Lee (1969) proposed the first phylogeny of East Asian Tingidae on the basis of larval characters. Seidenstücker (1954), considered the presence of larval outgrowths to be a primitive character. Stusák \& Štys (1959) pointed out the translocation phenomenon on some Palearctic species. Recent studies of the evolution of Tingidae (Guilbert, 2001), integrating larval characters, suggest that adults and larvae turned simple to complex through evolution by developing pronotal and hemelytral expansions and dorsal outgrowths respectively. Both adults and nymphs increase in size and acquire diverse shapes that in some cases become exaggerated (sensus Emlen \& Nijhout, 2000). Such characters are involved in complex behaviours like maternal brood care (Loeb et al., 2000; Tallamy \& Denno, 1981; Tallamy \& Schaefer, 1997), and larval defence strategies (Aldrich et al., 1991; Mason et al., 1991; Scholze, 1992). Knowledge of larvae would provide information as important as that provided by adults for the study of the evolution of Tingidae and their complex behaviour.
In order to study larval development of Tingidae, sampling surveys by fogging were conducted in New Caledonia to collect adults as well as different immature stages. The New Caledonian fauna of Tingidae includes 33 known species, of which $84 \%$ are endemic. This fauna was known until 1997 by seven endemic species; since then, 26 others have been recently described (Guilbert, 1997a, b, 1998a, b, 2000, 2002). The present paper describes different immature stages of nine species. Specimens are all deposited at the Muséum national d'Histoire naturelle, Paris, unless otherwise specified. All measurements are given in $\mathrm{mm}$.

\section{DESCRIPTIONS OF LARVAE}

\section{Agaotingis pindai Guilbert 2002 \\ (Figs 1, 2)}

Material. One second instar and one fourth instar: New Caledonia, Pindai peninsula, sclerophyllous forest, sample by fogging, 6.x.1992, Chazeau J., Bonnet de Larbogne L. and Guilbert E. coll., MNHN.

\section{Description}

Second instar (Fig. 1).

Body yellowish to brown, moderately broad, partly covered with tiny processes around the median abdominal tubercles and the glandular orifices. Legs and antennae whitish. Body length: 0.84; width: 0.57.

Head small, armed with five long, slender, erected tubercles, a median one, a frontal and an occipital pairs, the frontal pair shorter. Antennae long and slender; antennal segment measurements: I: 0.06; II: 0.03; III: 0.26; IV: 0.23 .

Pronotum moderately extended laterally at each side of the head, with a pair of simple, long and slender tubercles on the middle on both sides of the exuvial suture; each lateral margin with a long and slender tubercle on its posterior tip, and two shorter tubercles on the anterior part. 

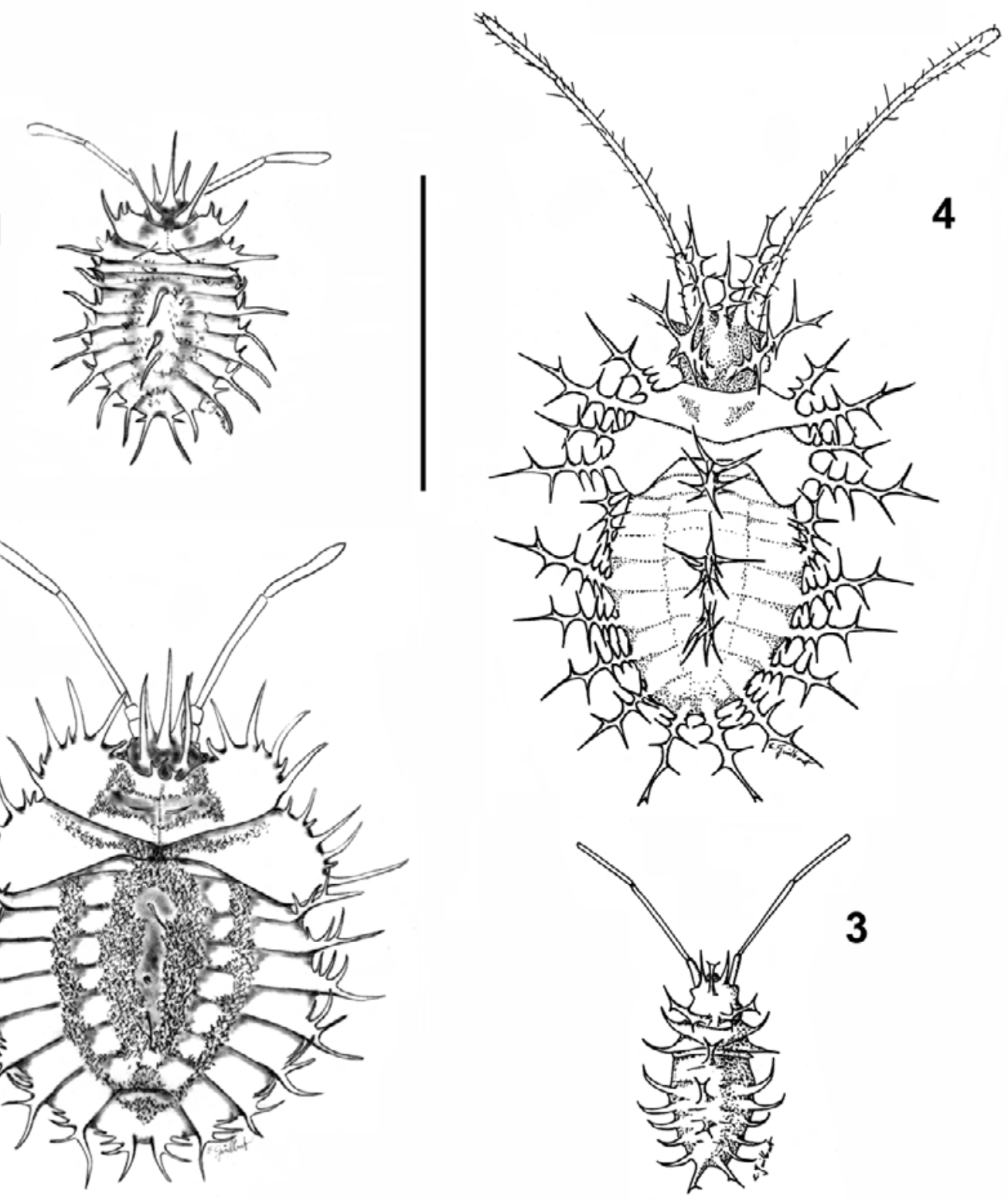

Figs 1-4. 1 - Agaotingis pindai Guilbert 2002, second instar habitus. 2 - Agaotingis pindai Guilbert 2002, fourth instar habitus. 3 - Cephalidiosus longispini Guilbert 2002, second instar habitus. 4 - Cephalidiosus longispini Guilbert 2002, fourth instar habitus. Scale $=1 \mathrm{~mm}$.

Mesonotum slightly extended laterally, with a long and slender tubercle on posterior tip of each margin, and two shorter tubercles on its anterior part.

Abdominal tergites with a tubercles on posterior tip of margins; tubercles long and slender, spiny, with a ramification at base directed forwards; second, fifth and sixth tergites with a median tubercle, these tubercles long, slender and spiny, directed upwards. Maximal tubercles length: 0.2 .

Fourth instar (Fig. 2)

Body brown, rounded and broad, partly covered with tiny processes on center of pronotum and mesonotum, on abdomen around median tubercle and glandular orifices. Legs and antennae whitish. Body length: 1.50; width: 1.17 .
Head as in second instar. Antennal segment measurements: I: 0.10; II: 0.07; III: 0.47; IV: 0.37.

Pronotum wide, extended laterally beyond head, the margins slightly raised, with a pair of small, short, bifid and spiny tubercles on anterior margin, directed forwards between two occipital cephalic tubercles; a pair of short, slender, spiny tubercles on each side of exuvial suture; margins with four long, slender, spiny, erected tubercles and three intermediate tubercles shorter than the four others; tiny processes distributed all around two median tubercles in two transversal rows.

Margins of hemelytral pads with four long, slender, spiny, erected tubercles, and three intermediate ones, shorter than the four major. Processes distributed on a transversal row across the anterior part of hemelytra. 


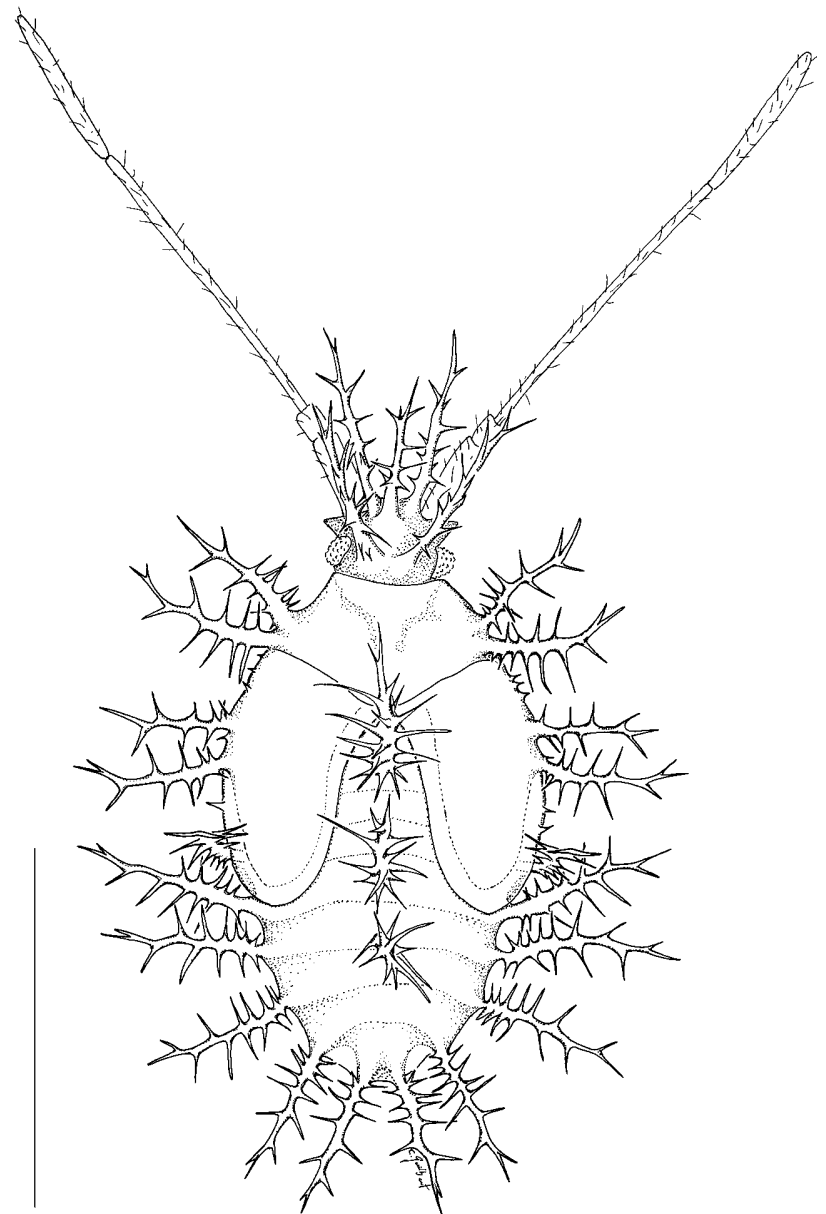

Fig. 5. Cephalidiosus longispini Guilbert 2002, fifth instar habitus. Scale $=1 \mathrm{~mm}$.

Margins of abdominal tergites with long, slender, spiny, erected, tubercles; each with three lateral, forwardly directed branches; second, fifth, and sixth tergites with a long, slender, spiny, erected tubercle on middle; tiny processes surrounding median tubercles and glandular orifices forming two oval rows.

The tubercles are long, slender, spiny, except anterior pronotal pair. Two types of marginal tubercles on pronotum and hemelytral pads are differing in their length. Only abdominal marginal tubercles are ramified; maximal tubercle length: 0.43. Processes pedonculate, star-like, and three- to four-branched.

Discussion. Agaotingis pindai is restricted to New Caledonia. This is the first larva of the genus Agaotingis described. It is easily distinguishable from larvae of other tingids of this fauna by the tubercles with ramifications only directed forwards, and by the distribution of the processes on the dorsum. In instars 2-4, marginal tubercles on abdominal tergites become one-branched to threebranched, pronotum and mesonotum acquire more marginal tubercles, the tubercle size increases, and the pronotum acquires also a pair of short bifid tubercles on its anterior margin.

Cephalidiosus longispini Guilbert 2002

(Figs 3, 4, 5)
Material. One second instar, one fourth instar, two fifth instars, New Caledonia, Rivière Bleue (P7), dense evergreen forest, sampled by fogging, 24.x.1992, Chazeau J., Bonnet de Larbogne L. and Guilbert E. coll., MNHN.

\section{Description}

\section{Second instar (Fig. 3)}

Body whitish, glabrous, smooth, without processes. Body length: 0.67; width: 0.27.

Head small, armed with five tubercles; frontal tubercles long, slender, and spiny, median tubercles long, slender, and bifid at the apex, occipital tubercles the longest, bifid at apex and with two ramifications on sides. Antennal segment measurements: I: 0.13; II: 0.03; III: 0.33; IV: 0.27 .

Pronotum and mesonotum with a tubercles on the posterior tip of margins, tubercles long, slender, and spiny.

Fourth to ninth abdominal tergites with a long, slender tubercles curved upwards on posterior tip of margins. Second, fifth, and sixth tergites with a median tubercle on middle, tubercles bifid at the apex, and erected. Maximal tubercle length, 0.23 .

Fourth and fifth instars (Figs 4, 5).

Fourth and fifth instars not differing except by body size and size of mesonotum. The description below applies to both instars.

Body whitish, glabrous, smooth, without any processes on surface. Body length: Fourth instar: 0.67; fifth instar: 1.5. Width: Fourth instar: 0.67; fifth instar: 0.83 .

Head glabrous, armed with five long, slender, straight, ramificate tubercles, a median one, a frontal, and an occipital pair; tubercles with long ramifications, all ending with a long seta. Antennae long and slender, with few short hairs. Antennal segment measurements: Fourth instar: I: 0.17; II: 0.06; III: 0.73; IV: 0.43; fifth instar: I: 0.23; II: 0.13; III: 0.77 ; IV: 0.43 .

Margins of pronotum armed with two tubercles on each side.

Margins of hemelytral pads armed with two tubercles on each side.

Margins of abdominal tergites armed with a tubercle. Second, fifth, and sixth tergites with a median tubercle on middle.

Tubercles long, spiny, ramified, with around 10 long ramifications, each with short spiny seta apically. Maximal tubercle length: fourth instar: 0.60; fifth instar: 0.57 .

Discussion. The species, as well as the genus, are endemic to New Caledonia. This is the only known larva of the genus. It is easily distinguishable from the other species in this fauna by the long ramified and spiny tubercles of the head and the body. From the second instar to fourth and fifth, the tubercles' distribution is the same, however, the median cephalic and abdominal tubercles become bifid to ramified, and the frontal and marginal tubercles become simple to ramified. The occipital tubercles were already ramified, but they acquired more ramifications. 


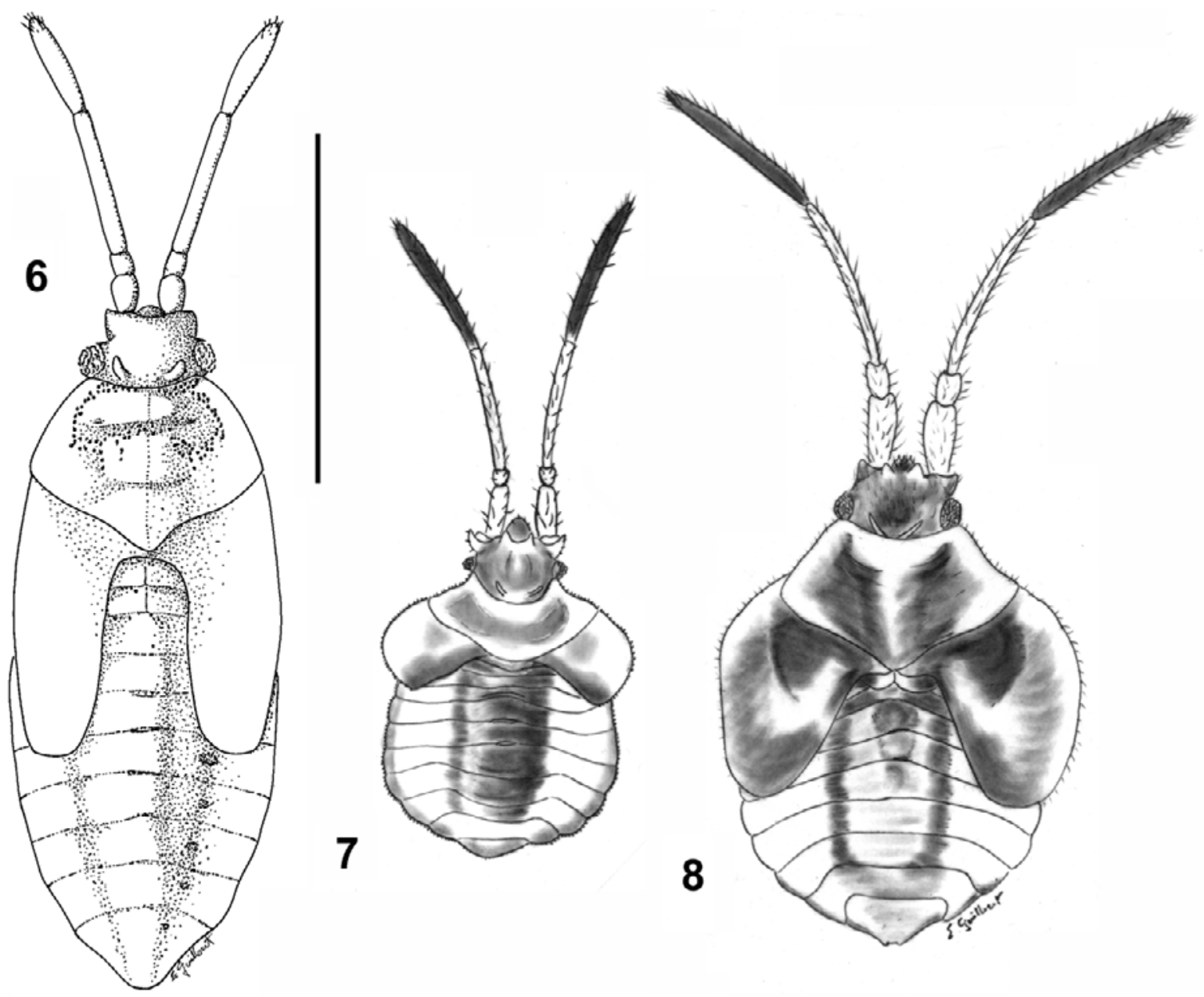

Figs 6-8. 6 -Epimixia nigriceps (Signoret 1881), fifth instar habitus. 7 -Nobarnus albiceps Guilbert 1997, fourth instar habitus. 8 - Nobarnus albiceps Guilbert 1997, fifth instar habitus. Scale $=1 \mathrm{~mm}$.

\section{Epimixia nigriceps (Signoret 1881)}

(Fig. 6)

Material. One fifth instar, New Caledonia, vallée d'Amoa, 7.ii.1963, G. Kuschel coll., Bishop Museum; one fifth instar, New Caledonia, Moubo, 150 m, 17.i.1964, R. Straatman coll., Bishop Museum; one fifth instar, New Caledonia, hills behind Nouméa, 15.viii.1940, F.X. William coll., beaten ex. of dwarf Casuarina, Bishop Museum. Deposited at the Bishop Museum.

\section{Description}

\section{Fifth instar (Fig. 6)}

Body, head, and legs dark brown; lateral margins of pronotum and mesonotum, abdomen, antenniferous processes, and occipital tubercles yellowish. Body narrow, glabrous, with some tiny granulous processes on pronotum and at base of metanotum, and first and second abdominal tergites. Body length: 1.43; width: 0.70 .

Head broad, with stout antenniferous processes, armed with a pair of occipital tubercles, tubercles short, stout, adpressed onto head. Antennal segment measurements: I: 0.10; II: 0.07; III: 0.3; IV: 0.17 .

Pro-, meso-, metanotum, and abdominal tergites narrow and straight, without tubercles.

Discussion. The species is endemic to New Caledonia, while the genus is also known from Australia. Like the adult, the larva does not exhibit any kind of expansion or outgrowth. This, the only known larvae of the genus, is similar to the larva of Perissonemia rectisulca described below, but distinguishable by the lack of the median tubercles on the anterior margin of the pronotum, and the differently shaped occipital tubercles.

\section{Nobarnus albiceps Guilbert 1997 \\ (Figs 7, 8)}

Material. Three second instars, one third instar, two fourth instars, three fifth instars, New Caledonia, Mont Nondoué near Pad'ta, sclerophylous forest, 3.vii.1992, sampled by fogging, Chazeau J., Bonnet de Larbogne L. and Guilbert E. coll., MNHN. One second instar, two third instars, five fourth instars, six fifth instars, New Caledonia, Mont Nondoué near Pad'ta, sclerophylous forest, 16.x.1992, sampled by fogging, Chazeau J., Bonnet de Larbogne L. and Guilbert E. coll., MNHN.

\section{Description}

The general morphology does not vary through the different instars. The body gets broader and the mesonotum longer so as to form the hemelytral pads through the different instars. Therefore, the description below considers all of them (Figs 7, 8 respectively fourth and fifth instars).

Body mostly whitish; pronotal part corresponding to collar, a spot on anterior part, and on posterior part of the hemelytra, middle part of abdominal tergites, and head, 

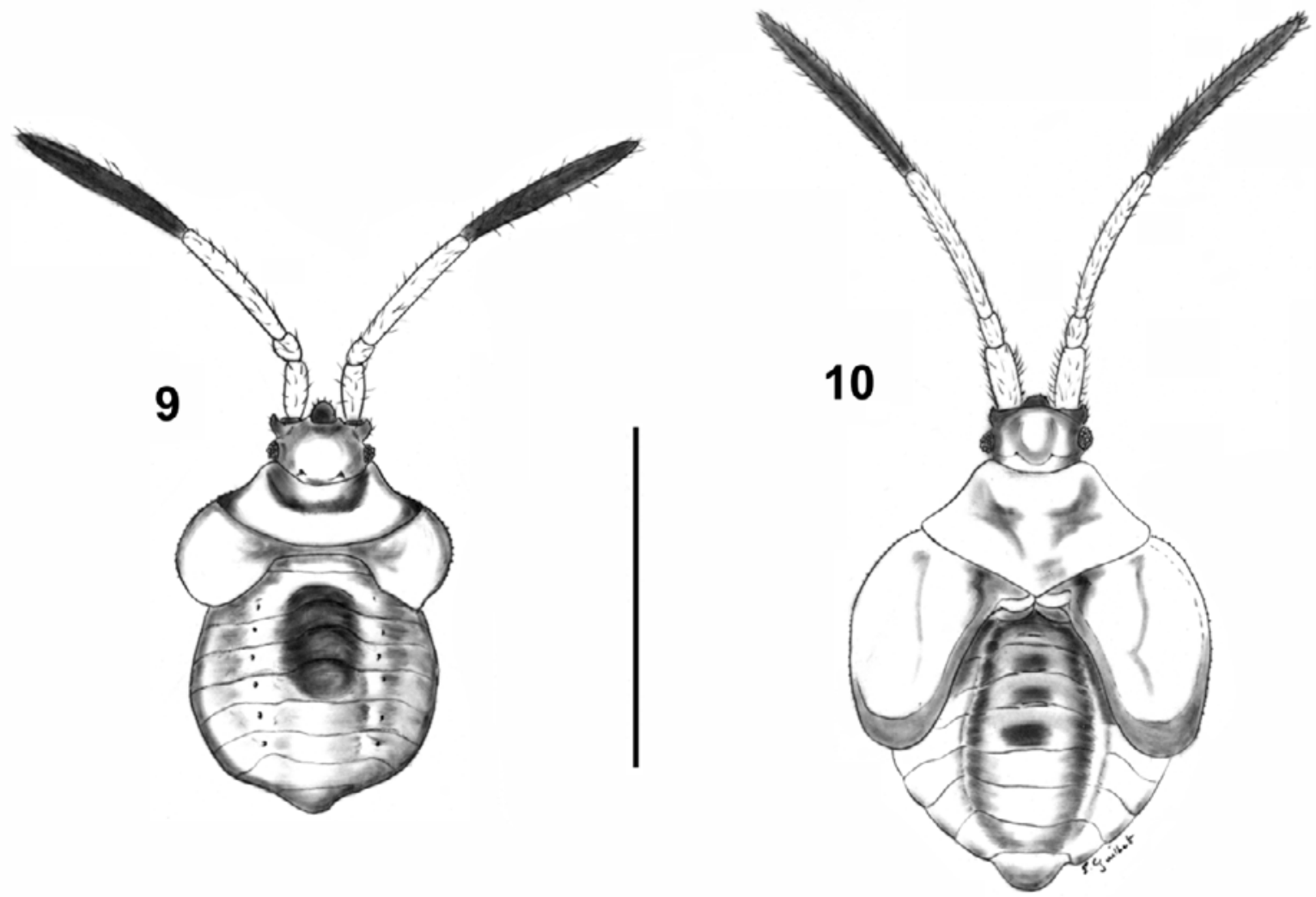

Figs 9-10. 9 - Nobarnus nigriceps Guilbert 1997, fourth instar habitus. 10 - Nobarnus nigriceps Guilbert 1997, fifth instar habitus. Scale $=1 \mathrm{~mm}$.

clear brown to brown; last antennal segment dark brown. Body length: second instar: 0.67; third instar: 0.90; fourth instar: 1.20; fifth instar: 1.60; width: second instar: 0.43 ; third instar: 0.50 ; fourth instar: 0.71 ; fifth instar: 1.20 .

Head large, glabrous, without tubercles; antenniferous processes spiny. Antennae long; the two first segments stouter than two last ones, sparsely covered with short hairs; antennal segment measurements: second instar: I: 0.07; II: 0.03; III: 0.23; IV: 0.40; third instar: I: 0.10; II: 0.07; III: 0.33 ; IV: 0.47 ; fourth instar: I: 0.17 ; II: 0.05 ; III: 0.40 ; IV: 0.5 ; fifth instar: I: 0.23 ; II: 0.10 ; III: 0.60; IV: 0.73 .

Pronotum and hemelytral pads wide and widened posteriorly, glabrous, smooth, without tubercle; with small setae all along margins.

Abdominal tergites smooth and glabrous, without tubercle; the intermediate tergites broadly swollen.

\section{Nobarnus nigriceps Guilbert 1997}

(Fig 9, 10)

Material. Seven second instars, three third instars, two fourth instars, two fifth instars, New Caledonia, Rivière Bleue (P6), dense evergreen forest, 16.vii.1992, sampled by fogging, Chazeau J., Bonnet de Larbogne L. and Guilbert E. coll., MNHN; two first/second instars, three fourth instars, New Caledonia, Rivière Bleue, (P6), dense evergreen forest, 21.x.1992, sampled by fogging, Chazeau J., Bonnet de Larbogne L. and Guilbert E. coll., MNHN; one second instar, one fifth instar, New Caledonia, Rivière Bleue (P6), dense evergreen forest, 8.v.1993, sampled by fogging, Chazeau J., Bonnet de Larbogne L. and Guilbert E. coll., MNHN; two second instar, one fourth instar, two fifth instars, New Caledonia, Rivière Bleue (P7), dense evergreen forest, 21.vii.1992, sampled by fogging, Chazeau J., Bonnet de Larbogne L. and Guilbert E. coll., MNHN; three first instars, five second instars, one fourth instar, four fifth instars, New Caledonia, Rivière Bleue (P7), dense evergreen forest, 24.x.92, sampled by fogging, Chazeau J., Bonnet de Larbogne L. and Guilbert E. coll., MNHN.

\section{Description}

As in Nobarnus albiceps, the overall morphology does not vary through the different instars. The body gets broader and the mesonotum longer so as to form the hemelytra through the different instars. Therefore, the description below considers all of them (Figs 9, 10 respectively fourth and fifth instars).

Body mostly whitish; pronotal part corresponding to the collar, a spot on anterior part and on posterior part of hemelytra, middle part of abdominal tergites, and head, clear brown to brown; last antennal segment dark brown. Body length: second instar: 0.83; third instar: 1.07; fourth instar: 1.33; fifth instar: 1.50; width: second instar: 0.43 ; third instar: 0.53 ; fourth instar: 0.80 ; fifth instar: 1.17 .

Head large, covered with tiny setae dorsally; with two pairs of small tubercles, frontal one small, short, base stout and the apex slender, straight, and directed forwards; occipital one very small and short, base covered by pronotum. Antenniferous process covered with short hairs at the apex; antennae with long hairs; antennal segment measurements: second instar: I: 0.10; II: 0.05; III: 0.23; IV: 0.23; third instar: I: 0.13; II: 0.07; III: 0.33; IV: 

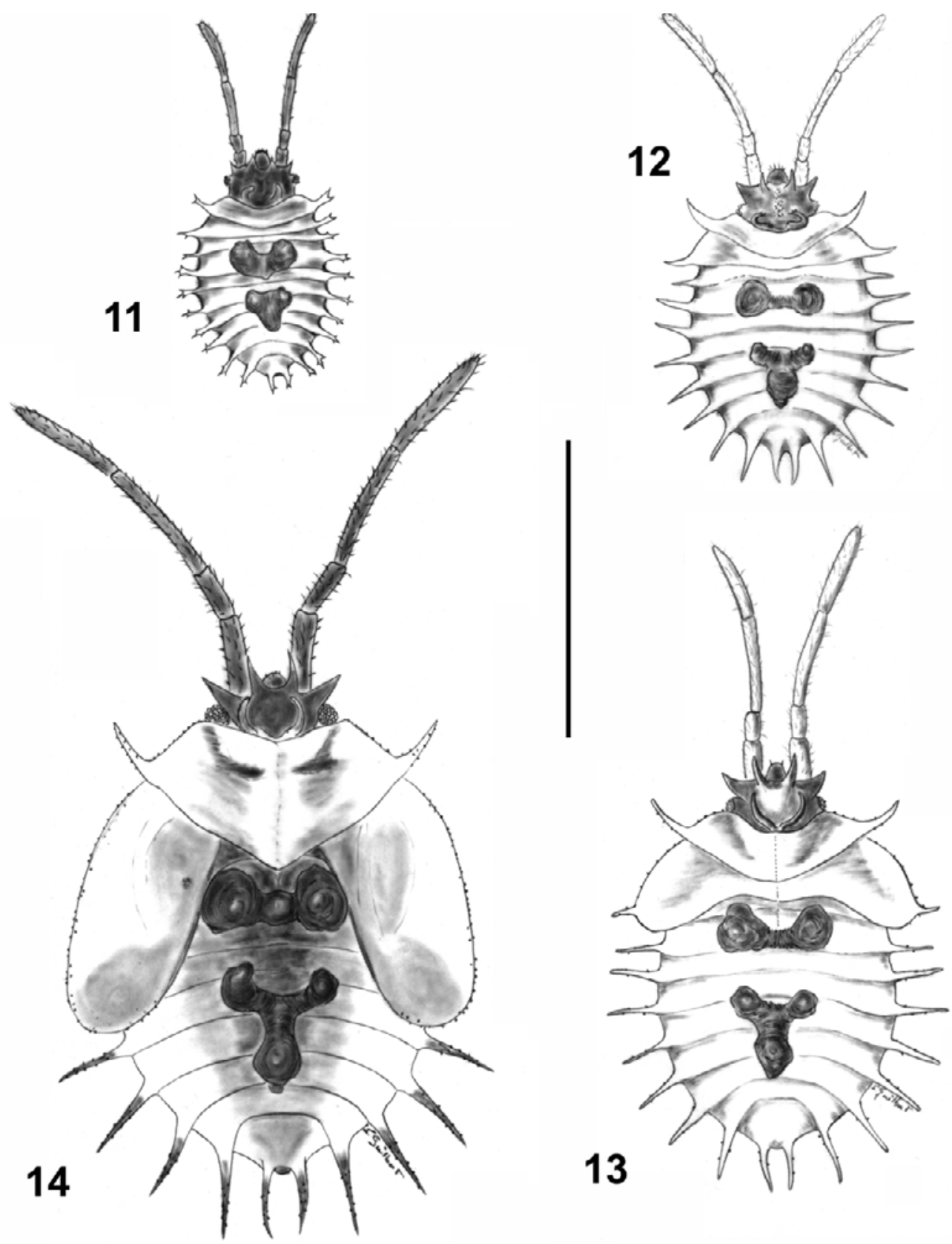

Figs 11-14. 11 - Nobarnus pilosus Guilbert 1997, second instar habitus. 12 - Nobarnus pilosus Guilbert 1997, third instar habitus. 13 - Nobarnus pilosus Guilbert 1997, fourth instar habitus. 14 - Nobarnus pilosus Guilbert 1997, fifth instar habitus. Scale $=1 \mathrm{~mm}$.

0.50; fourth instar: I: 0.20 ; II: 0.07 ; III: 0.43 ; IV: 0.67 ; fifth instar: I: 0.23 ; II: 0.10 ; III: 0.53; IV: 0.60 .

Pronotum wide and widened posteriorly, glabrous, smooth, without tubercle.

Hemelytral pads wide, glabrous, smooth, without tubercle but with small setae all along margins.

Abdominal tegites smooth and glabrous, without tubercle; intermediate tergites broadly swollen.

\section{Nobarnus pilosus Guilbert 1997}

(Figs 11, 12, 13, 14)

Material. One third instar, New Caledonia, Rivière Bleue, (P6), dense evergreen forest, 21.x.1992, sampled by fogging, Chazeau J., Bonnet de Larbogne L. and Guilbert E. coll., MNHN; one second instar, one fifth instar, New Caledonia,
Rivière Bleue (P7), dense evergreen forest, 21.vii.1992, sampled by fogging, Chazeau J., Bonnet de Larbogne L. and Guilbert E. coll., MNHN; one third instar, one fourth instar, New Caledonia, Rivière Bleue (P7), dense evergreen forest, 24.x.1992, sampled by fogging, Chazeau J., Bonnet de Larbogne L. and Guilbert E. coll., MNHN.

\section{Desription}

Second instar (Fig. 11).

Body mostly whitish to yellowish; head, antennae, median abdominal tubercles dark brown. Body length: 0.83; width: 0.60 .

Head broad, armed with a frontal pair of short spiny tubercles and an occipital pair of short, stout tubercles curved inwards, antenniferous processes sharp, antennae 

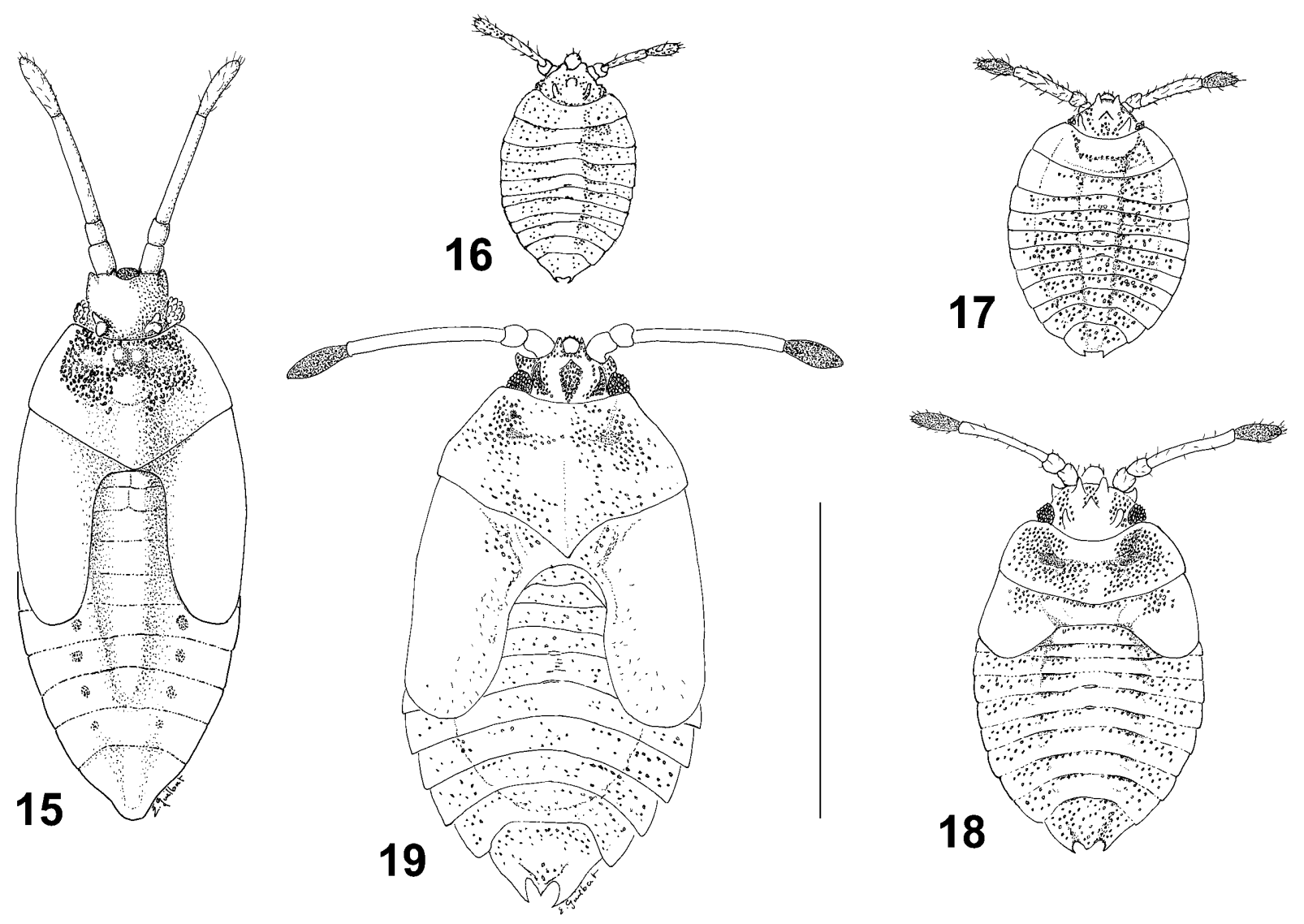

Fig. 15-19. 15 - Perissonemia rectisulca Guilbert 2002, fifth instar habitus. 16 - Physatocheila dissimilis Guilbert 1997, second instar habitus. 17 - Physatocheila dissimilis Guilbert 1997, third instar habitus. 18 - Physatocheila dissimilis Guilbert 1997, fourth instar habitus. 19 - Physatocheila dissimilis Guilbert 1997, fifth instar habitus. Scale $=1 \mathrm{~mm}$.

stout, moderately long, and scarcely pilose. Antennal segment measurements: I: 0.07; II: 0.03; III: 0.17; IV: 0.17 .

Pronotum and mesonotum short but slightly widened laterally and posteriorly, with a short, bifid tubercle on posterior tip of margins.

Abdominal tergites with a bifid to trifid tubercle on posterior tip of margins; second and fifth abdominal tergites with a median tubercle; tubercle on second tergite made of two globular outgrowths connected in middle of the tergite, erected upwards and slightly directed forwards; tubercle on fifth tergite made of two globular outgrowths directed upwards, connected to the middle, and a median outgrowth directed backwards but not erected. Maximal tubercles length, 0.10 .

Third and fourth instars (Figs 12, 13 respectively).

Third and fourth instars exhibit the same morphology, except for the body size and the hemelytra development. There are described together below.

Body coloration as second instar. Body length: third instar: 1.03; fourth instar: 1.50; width: third instar: 0.70 ; fourth instar: 1.03

Head broad, armed with an occipital and a frontal pair of long and slender tubercles, occipital pair curved inwards, frontal pair directed forwards; antenniferous processes long and spiny; antennae long, stout, and pilose. Antennal segment measurements: third instar: I:
0.13; II: 0.07; III: 0.3; IV: 0.33; fourth instar: I: 0.20; II: 0.13; III: 0.40; IV: 0.37 .

Pronotum abruptly widened posteriorly, with a long, slender tubercle slightly curved forwards on posterior tip of margins. Mesonotum widened posteriorly, with a long slender tubercle on posterior tip of margins; tubercles in fourth instar shorter than in third instar.

Abdominal tergites with a long, slender, and spiny tubercle on posterior tip of margins; second and fifth tergites with a median tubercle; tubercles of same shape as on second instar, but outgrowths and connections larger. Maximal tubercle length: third instar: 0.17; fourth instar: 0.20 .

Fifth instar (Fig. 14).

Body mostly whitish to yellowish; pronotal part corresponding to the collar, a spot on anterior part and on posterior part of hemelytra, middle part of abdominal tergites, pronotal and hemelytral margins, tip of the tubercles clear brown to brown; antennae and legs brown, head, abdominal median tubercles and glands orifices brown fuscous to black. Whole body glabrous, smooth, without processes. Body length: $1.83 \mathrm{~mm}$, width: 1.60 $\mathrm{mm}$.

Head large, armed with a frontal pair of straight, long and slender tubercles, directed forwards, and an occipital pair of long, slender, curved inwardly tubercles; occipital 
tubercles longer than frontal ones; antenniferous processes long and spiny; antennae long and stout, first two antennal segments slightly stouter than two last ones, covered with scarce, short hairs. Antennal segment measurements: I: 0.27; II: 0.17; III: 0.53; IV: $0.47 \mathrm{~mm}$.

Pronotum wide, armed with a long, slightly curved, slender, spiny tubercle on each posterior tip of margins and directed forwards, margins bearing small bulbs, each with a short seta apically.

Hemeytral pads without tubercles but with, on whole margins, small bulbs with a short seta apically.

Abdominal tergites armed with a simple, long tubercle on posterior part of each margin; second and fifth tergites with a median tubercle; median tubercle on second tergite made of a pair of smooth and glabrous globules or cysts; median tubercle on fifth tergite made of a pair of wide, curved, and erected, globular outgrowth with a posterior globular expansion covering middle of sixth tergite and directed backwards; small tubular processes from first to sixth tergites, surrounding median tubercle and glands orifices.

The tubercles are long spiny and simple, without ramifications, but with some tiny bulbs and setae. Maximal tubercle length: $0.47 \mathrm{~mm}$.

Discussion. The marginal tubercles, bifid to trifid in the second instar become simple and increase in size through the third to fifth larval stages, except thet the one on mesonotum is shorter in the fourth instar and disappears in the fifth instar. The median tubercles on the second and fifth abdominal tergites are present through all larval stages, and also increase in size. $N$. pilosus is distinguishable from all other known larvae by the remarkable tubercles on the second and fifth abdominal tergites.

Nobarnusis restricted to New Caledonia and groups six species. The larvae have a broad body, and the adults have broad hemelytra. $N$. albiceps and $N$. nigriceps are very similar, but distinguishable by the colour of the head and the body, and also by the cephalic tubercles which are lacking in $N$. albiceps and present in $N$. nigriceps. Both larvae differ from $N$. pilosus by the lack of thoracic and abdominal tubercles.

\section{Perissonemia rectisulca Guilbert 2002}

(Fig. 15)

Material. One fifth instar, New Caledonia, $3 \mathrm{~km} \mathrm{SE}$ of La coulée, 23.i.1963, C.M. Yoshimoto coll., Bishop Museum. Deposited at the Bishop Museum.

\section{Description}

Fifth instar (Fig. 15).

Body narrow, yellowish to brown, posterior part of abdomen, middle of hemelytra, lateral margins of pronotum, tubercles, antenniferous processes, and two first antennal segments clearer; legs and two last antennal segments darker. Body length: 1.97; width: 0.83 .

Head broad, armed with two pairs of tubercles; frontal tubercles tiny, occipital tubercles globular, short and stout, somewhat bifid from base; antenniferous processes short and spiny; antennae moderately long and stout.
Antennal segment measurements: I: 0.13; II: 0.10; III: 0.40; IV: 0.30 .

Pronotum narrow but regularly widened backwards, partly covered with granular processes on the part, with a median pair of tubercles near anterior margin; tubercles, short, stout, globular.

Mesonotum, metanotum, and abdominal tergites narrow, without tubercle, but with some granular processes on base of mesonotum, metanotum, and first abdominal tergite.

Discussion. This species is endemic to New Caledonia. The larva is the only one known in the genus. It is similar to the larvae of Epimixia nigriceps; however, it can be separated by the median pair of bulbous tubercles on the anterior margin of the pronotum.

\section{Physatocheila dissimilis Guilbert 1997}

(Figs 16, 17, 18, 19)

Material. Four second instars, three third instars, four fourth instars, three fifth instars, New Caledonia, Pindai peninsula, sclerophyllous forest, sampled by fogging, 30.vi.1992, Chazeau J., Bonnet de Larbogne L. and Guilbert E. coll., MNHN.

\section{Description}

The four instars have the same morphology except for the different sizes and the development of the hemelytra. Thus, the description below concerns all larval stages (Figs 16, 17, 18, 19, respectively the second, third, fourth, and fifth instars).

Body yellowish, glabrous, covered with tiny granulelike processes. Body length: second instar: 0.73; third instar: 1.00; fourth instar: 1.33; fifth instar: 1.93; width: second instar: 0.50 ; third instar: 0.67 ; fourth instar: 0.80 ; fifth instar: 1.10 .

Head wide, armed with two pairs (frontal and occipital) of slender tubercles slightly curved and directed forwards, and a median short and stout tubercle. Antennae moderately long; antennal segment measurements: second instar: I: 0.03; II: 0.03; III: 0.13; IV: 0.10; third instar: I: 0.07; II: 0.05; III: 0.13; IV: 0.10; fourth instar: I: 0.07; II: 0.07; III: 0.33; IV: 0.20; fifth instar: I: 0.10; II: 0.07; III: $0.53 ;$ IV: 0.20 .

Pronotum margins extending a little laterally beyond each side of head, without tubercle.

Mesonotum and metanotum without tubercle.

Abdominal tergites flat, without tubercle, posterior tip of margins slightly extended backwards, except the ninth tergite bearing two short hook-like tubercle at posterior tip.

Discussion. This species is restricted to $\mathrm{New}$ Caledonia. The larvae are easily distinguishable by the hook-like tubercles on the ninth tergite and the tiny granular processes on the dorsum.

\section{Tingis irregularis (Montrouzier 1861)}

(Fig. 20)

Material. One fourth instar, New Caledonia, Mont Nondoué near Païta, sclerophylous forest, 03.vii.1992, sampled by fogging, Chazeau J., Bonnet de Larbogne L. and Guilbert E. coll., MNHN. 


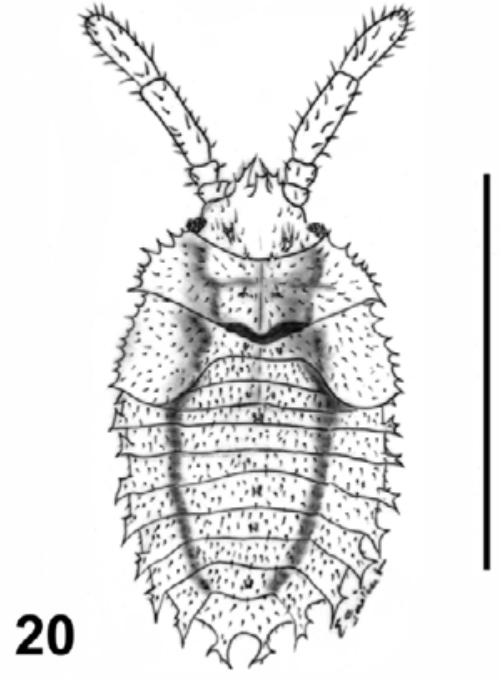

Fig. 20. Tingis irregularis (Montrouzier 1861), fourth instar habitus. Scale $=1 \mathrm{~mm}$.

\section{Description}

Fourth instar (Fig. 20).

Body yellowish to clear brown, middle of body darker, glabrous but covered by small tubular processes. Body length: $1.3 \mathrm{~mm}$; width: $0.80 \mathrm{~mm}$.

Head armed with five small tubercles, the frontal pair simple, bearing setae at the apex, longer than occipital pair, the occipital pair bifid, bearing two setae at apex, median tubercle stouter than others, also bearing two setae at apex. Antennae stout, short, and moderately pilose; antennal segment measurements: I: 0.07; II: 0.07; III: 0.27; IV: $0.20 \mathrm{~mm}$.

Pronotum with two pairs of minute, short processes on each side of exuvial suture, one on middle of pronotum, and one on anterior margin, and several short tubercles along lateral margins, last posterior tubercle of margins bigger than other.

Margins of hemelytral pads with several small tubercles with a setae at the apex.

Mesonotum and first abdominal tergite with a tiny tubercle on each side of exuvial suture.

Margins of abdominal tergites with a small tubercle, with three to four setae; second, fifth, sixth, and eighth tergites each with a minute, bifid median tubercle.

Median tubercles very small, stout, bifid, each bifurcation bearing a bulbous or pestle-like seta. Pronotal and hemelytral marginal tubercles small, short, and simple (without bifurcation) and bear a single seta at the apex. Abdominal marginal tubercles are longer than other, stout, and spiny, with more than two setae, one at the apex, other seta on small bulbs on sides; maximal tubercle length: $0.07 \mathrm{~mm}$.

Discussion: The above description is based upon a fourth instar. Thus, the tubercles may develop later to longer and more ramified ones, as they do in other species. However, Tingis is a large genus and the morphology of Tingis larvae vary among species. Thus, no characteristics emerge to define the genus, as is also the case for adults. This species is restricted to New Caledo- nia, and is very similar to Eritingis species, which are mostly known from Australia. However, no larvae of Eritingis species are known.

\section{KEY TO NEW CALEDONIAN FIFTH INSTARS}

1 Abdominal marginal tubercles absent $\ldots \ldots \ldots \ldots \ldots 2$

Abdominal marginal tubercles present .......... 6

2 Frontal tubercle absent $\ldots \ldots \ldots \ldots \ldots \ldots \ldots \ldots \ldots$

- Frontal tubercle present ............ dissimilis

3 Body length more than twice its width ......... 4

- Body length less than twice its width ........... 5

4 Anteromedian tubercles on pronotum present $P$. rectisulca

Anteromedian tubercles on pronotum absent . E. nigriceps

5 Occipital tubercles very short, frontal tubercles absent ....

$\ldots \ldots \ldots \ldots \ldots \ldots \ldots \ldots \ldots \ldots \ldots \ldots \ldots \ldots \ldots$ nigreps

Occipital tubercles long, and frontal tubercles present $\ldots \ldots$ $\ldots \ldots \ldots \ldots \ldots \ldots \ldots$. albiceps

6 Thoracic marginal and cephalic occipital tubercles absent . $\ldots \ldots \ldots \ldots \ldots \ldots$. irregularis

Thoracic marginal and cephalic occipital tubercles present 7

7 Cephalic and thoracic marginal tubercles simple and spiny 8

Cephalic and thoracic marginal tubercles ramified ...... $\ldots \ldots \ldots \ldots \ldots \ldots \ldots \ldots$. longispini

8 Mesonotal marginal tubercles absent ........ N. pilosus

Mesonotal marginal tubercles present ........ A. pindai

\section{DISCUSSION}

Few fifth instars are known, and even fewer earlier instars. The larvae described in the present work are the only ones known of New Caledonian Tingidae. Tubercle and process structures of New Caledonian larvae resemble those of other known larvae. Many species (Acalypta spp., Copium spp., Agramma spp., Catoplatus spp.) have larvae without any outgrowth on the dorsum. Others have simple spiny tubercles, like Stephanitis species; and others have ramificate tubercles, like Tingis and Ammianus species. Many variations exist among the main tubercle shapes. For example, C. longispini and Tingis buddleiae Drake have similar ramified tubercles, but the ramification are oriented on the same plane in C. longispini, while they are oriented in various directions in $T$. buddleiae. In addition, the apical seta of each ramification is shorter in C. longispini than in T. buddleiae. Some species exhibit new shapes never encountered in other larvae. The ramifications on tubercles in $A$. pindai are all directed forwards, while they are directed forwards and backwards in C. longispinus. Such a wide range of shapes could be related with the wide range of host plants, as outgrowths could have a clinging function, as suggested by Seidenstücker (1954) and Péricart (1983). The two median abdominal tubercles in $N$. pilosus are characteristic of the species and have never been observed on other larvae. Such tubercles remain the strongly produced structure asociated with the first opening of dorsal glands of Symphylax picticollis Horváth (1904 (Štys, 1977). However, the tubercles in N. pilosus are not associated with the opening of the dorsal glands, and have a different shape (Fig. 14). Their unusual shape raises the question of homology with the median dorsal tubercles found in other Tingidae larvae. 
TABLE 1. Number of marginal tubercles on pronotum, mesonotum (hemelytral pads), metanotum, and abdomen through the different immature stages of the spiny larvae of New Caledonian species. The fourth instar of $T$. irregularis is not represented because this is the only known immature stage of this species.

\begin{tabular}{lccccc}
\hline Species & $\begin{array}{c}\text { Location } \\
\text { of tubercles }\end{array}$ & $\begin{array}{c}\text { Instar } \\
\text { II }\end{array}$ & $\begin{array}{c}\text { Instar } \\
\text { III }\end{array}$ & $\begin{array}{c}\text { Instar } \\
\text { IV }\end{array}$ & $\begin{array}{c}\text { Instar } \\
\text { V }\end{array}$ \\
\hline A. pindaii & Pronotum & 3 & & 7 & \\
& Mesonotum & 3 & & 7 & \\
& Metanotum & 1 & & 0 & \\
C. longispini & Abdomen & 8 & & 8 & \\
& Pronotum & 1 & & 2 & 2 \\
& Mesonotum & 1 & & 2 & 3 \\
& Metanotum & 1 & & 0 & 0 \\
& Abdomen & 6 & & 6 & 6 \\
& Pronotum & 1 & 1 & 1 & 1 \\
& Mesonotum & 1 & 1 & 1 & 0 \\
& Metanotum & 1 & 1 & 0 & 0 \\
& Abdomen & 8 & 8 & 8 & 5 \\
\hline
\end{tabular}

The process shapes also vary among species. They can be star-like (A. pindai), granule-like (E. nigriceps, $P$. rectisulca, $P$. dissimilis), or tubular (N. pilosus, T. irregularis). Unlike tubercles, process shape does not change through larval stages, when present.

Development of tubercles through instars is different according to species. In $P$. dissimilis, the instars as well as the adult do not differ with respect to the tubercles: they all bear five cephalic tubercles. In species such as N. albiceps and $N$. nigriceps, there is no remarkable difference between the instars as they do not bear any tubercles on the body, except the cephalic one (frontal and occipital). However, the adult loses the occipital tubercles in both species. Similarly, the N. pilosus fifth instar loses the mesonotal marginal tubercles; while all other marginal tubercles become simpler from the second to the third instar. Cephalidiosus longispini and $A$. pindai show the opposite, as the marginal tubercles in both species and the cephalic tubercles in $C$. longispini become ramified, and then more complex from the second to the fourth instars. The adults of both species conserve the cephalic tubercles, which become simple. As a general rule, larvae become more complex as they develop through successive instars. Many other known larvae have tubercles, whose size and number of ramifications increase. For example, this is the case of Tingis beesoni (Mathur, 1955), Tingis stachydis (Štusák, 1968), and Urentius euonymus (Livingstone, 1959).

Such a development was also observed in East Asian Tingidae (Lee, 1969). Among these tingids, the case of Cochlochila lewisi (Scott) reminds one of the phenomenon of translocation suggested by Štusák \& Štys (1959), and commented on by Péricart (1983). Cochlochila lewisi acquires two more tubercles on the margins of the pronotal and hemelytral pads through larval development. Hemelytral pads acquire new outgrowths on their margins through the last instars in replacement of outgrowths of metanotal and first abdominal margins, which are covered by hemelytral pads. This is also the case in Dictyla humuli (Fabricius), which acquires marginal tubercles on the mesonotum, replace the lost of marginal tubercles on the metanotum and first abdominal tergites. If translocation of outgrowths is the general rule, it is not observed in New Caledonian larvae. Cephalidiosus longispinus and $A$. pindai have a number of hemelytral marginal tubercles which increase through successive instars, while the number of abdominal marginal tubercles remains the same (Table 1). Nobarnus pilosus shows the opposite. It has tubercles in the first instar but loses them on the first, second, and third abdominal tergite margins in latter instars. These tubercles are not "replaced" by tubercles on the hemelytral pad margins. In fact, the hemelytral pads also lose their single marginal tubercles.

In summary, there are three cases. First, the number of marginal tubercles increases through development. Second, the number of marginal tubercles remains the same, mostly by translocation of marginal tubercles. Third, the number of marginal tubercles decreases. The increase in the number of marginal tubercles, as well as translocation phenomenon, is not in contradiction of the suggestion that spiny outgrowths facilitate the clinging function larvae have developed (Seidenstücker, 1954; Štusák \& Štys, 1959). Translocation could be an intermediate stage of evolution, in terms of acquiring more tubercles through instars. The decrease of marginal tubercles is an exception, as it is only observed in N. pilosus.

In addition to complexification through development, larvae are also more complex through evolution, as are their adults (Guilbert, 2001). Such a development suggest heterochrony, particularly peramorphosis (Brooks \& McLennan, 2002). The descendant adult morphology is more complex than that of its immediate ancestor (Brooks \& McLennan, 2002: 349). This is the case with tingid larvae according to Lee (1969) and Guilbert (pers. obs). Acquiring a tubercle is apomorphic. Therefore, the more tubercles appear, the more derived is the species. Seidenstücker (1954) suggested the opposite: outgrowths are primitive characters, because they are lost by the adults. However, Seidenstücker' suggestion is based on a morphogenetic study, while Guilbert's hypothesis is based on a cladistic analysis. From a cladistic point of view, shall we consider that the loss of tubercles at the adult stage is apomorphic or plesiomorphic?

Further studies of morphogenesis and ontogenesis are needed to consider such questions, and would greatly help in understanding the evolution of Tingidae. This study of New Caledonian larvae is part of the first step in this direction.

ACKNOWLEDGEMENTS. I am greatly indebted to J. Péricart, T. Bourgoin, C. d'Haese, V. Golub and P. Štys for their fruitful comments on the manuscript.

\section{REFERENCES}

Aldrich J.R., Neal J.W., Oliver J.E., Lusby W.R. 1991: Chemistry vis-à-vis maternalism in Lace bugs (Heteroptera: Tingidae): alarm pheromones and exudate defence in Corythucha and Gargaphia species. J. Chem. Ecol. 17: 2307-2322.

Brooks D.R. \& McLennan D.A. (eds) 2002: The Nature of Diversity. An Evolutionary Voyage of Discovery. UCP, Chicago, USA, 668 pp. 
Duarte Rodrigues P. 1977: Nymphs of Urenthius chobauti Horv., Tingis geniculata (Fieb.), Tingis liturata (Fieb.), and Dictyla variabilis Rodr. (Heteroptera, Tingidae). Arq. Mus. Bocage 8: 121-131.

DuARTE Rodrigues P. 1978: African Tingidae, III: nymphs of Dictyla burgeoni (Schout.), Mafa lanceolata Hesse and Agramma maynei (Schout.) (Heteroptera). Arq. Mus. Bocage 13: $241-249$.

Duarte Rodrigues P. 1979: African Tingidae, V: nymphs of Ammianus alaticollis (Stål), Dictyla flavipes (Signoret) and Compseuta ornatella (Stål) (Heteroptera). Arq. Mus. Bocage 24: $481-488$.

EMLen D.J. \& Nijhout H.F. 2000: The development and evolution of exaggerated morphologies in Insects. Annu. Rev. Entomol. 45: 661-708.

Guilbert E. 1997a: Two new species of Dicysta from New Caledonia (Hemiptera, Tingidae). Zoosystema 19: 515-521.

Guilbert E. 1997b: Nouveaux Tingidae (Hemiptera) de Nouvelle-Calédonie. Bull. Soc. Entomol. Fr. 102: 293-298.

Guilbert E. 1998a: Stenotrachelus: a new genus and two new species of Tingidae (Hemiptera) from New Caledonia. Austral. J. Entomol. 37: 17-21.

Guilbert E. 1998b: Revision of the New Caledonian genus Nobarnus (Hemiptera: Tingidae) with description of three new species. Eur. J. Entomol. 95: 395-406.

Guilbert E. 2000: Revision of the genus Parada (Tingidae: Hemiptera) with a cladistic analysis. Proc. Entomol. Soc. Wash. 102: 816-830.

Guilbert E. 2001: Phylogeny and evolution of exaggerated traits among the Tingidae (Cimicomorpha, Heteroptera). Zool. Scripta 30: 313-324.

Guilbert E. 2002: New data on New Caledonian Tingidae (Hemiptera) with description of new species. In Najt J. \& Grandcolas P. (eds): Zoologia neocaledonica 5. Systématique et endémisme en Nouvelle-Calédonie. Mém. Mus. Natl. Hist. Nat. 187: 133-160.

LeE C.E. 1969: Morphological and phylogenic studies on the larvae and male genitalia of the East Asiatic Tingidae (Heteroptera). J. Fac. Agric. Kyushu Univ. 15: 138-256.

Livingstone D. 1959: On the bionomics and immature sages of Urentius euonymus Dist. (Heteroptera: Tingidae). A sap sucker on Hollyhocks and other garden plants. In: Proceedings of the First All-India Congress of Zoology. Part. 2 Scientific paper. The Zoological Society of India, Calceutta, pp. 510-519.

LIVINGSTONE D. 1978: On the body outgrowths and the phenomenon of "sweating" in the nymphal instars of Tingidae (Hemiptera: Heteroptera). J. Nat. Hist. 12: 377-394.
Loeb M.L.G., Diener L.M. \& Pfennig D.W. 2000: Egg-dumping lace bugs preferentially oviposit with kin. Anim. Behav. 59: 379-383.

Mason J.R., Neal J., Oliver J.E., Lusby W.R. 1991: Birdrepellent properties of secretions from nymphs of the Azalea lace bug. Ecol. Appl. 1: 226-230.

MathuR R.N. 1955: Immature stages of Tingis beesoni Drake (Heteroptera: Tingidae). The Entomologist 88: 248-251.

MAY B.M. 1977: The immature stages and biology of the lacebug Tanybyrsa cumberi Drake (Heteroptera: Tingidae). $J$. R. Soc. New Zeal. 7: 303-312.

Péricart J. (ed.) 1983: Hémiptères Tingidae euro-méditerranéens. Faune de France. France et Régions Limitrophes. No. 69. Masson, Paris, 618 pp.

SCHOLZe W. 1992: "Sekretschwitzen" bei Netzwanzenlarven: Zur Morphologie, Chemie und biologischen Bedeutung von Integumentbildungen mit sekretorischer Funktion bei Netzwanzenlarven (Heteroptera, Tingidae). Dissertation, Universität Bayreuth, Bayreuth, 246 pp.

SeIDENSTÜCKER G. 1954: Monanthia triconula n. sp. und einige Tingiden aus der südlichen Türkei. Rev. Fac. Sci. Univ. Istanbul (B) 19: 231-236.

ŠTUSÁK J.M. 1968: Notes on the bionomics and immature stages of Tingis stachydis (Fieber) (Heteroptera, Tingidae). Acta Entomol. Bohemoslov. 65: 412-421.

ŠTusÁK J.M. 1974: Nymphs of Tingis angustata, with a key to last instar nymphs of the genus Tingis (Heteroptera, Tingidae). Acta Entomol. Bohemoslov. 71: 105-113.

ŠTuSÁK J.M. 1975: Catoplatus minor sp. n. from Bulgaria, with a key to last instar nymphs of Catoplatus (Heteroptera, Tingidae). Acta Entomol. Bohemoslov. 72: 164-170.

ŠTUSÁK J.M. \& ŠTYS P. 1959: Investigation of the taxonomy and morphology of imagines and nymphs of some species of the genus Monanthia Le Peletier et Serville, 1825. Acta Univ. Carol. (Biol.) 3: 177-205.

ŠTYS P. 1977: Revision of Symphylax (Heteroptera: Colobathristidae). Acta Zool. Acad. Sci. Hung. 23: 427-451.

Tallamy D.W. \& Denno R.F. 1981: Maternal care in Gargaphia solani (Hemiptera: Tingidae). Anim. Behav. 29: 771-778.

Tallamy D.W. \& Schaefer C. 1997: Maternal care in the Hemiptera: ancestry, alternatives, and current adaptative value. In Choe J.C. \& Crespi B.J. (eds): The Evolution of Social Behavior on Insects and Arachnids. CUP, Cambridge, pp. 94-115.

Received September 12, 2003; revised November 14, 2003; accepted January 12, 2004 